\title{
Longitudinal teaching of non-technical skills in prehospital emergency medical training
}

\section{Purpose of the study}

Non-technical skills (NTS), as part of so-called human factors, are interpersonal and cognitive skills[1]. Training of NTS aims to improve the performance of medical teams and to decrease medical errors. The Red Cross and the Medical University of Graz run the education program for medical students as rescue medics with special emergency skill intubation and artificial respiration (NKI-RM) in Graz, Austria. Purpose of this study is to design a longitudinal concept integrating NTS in NKI-RM education and test its feasibility by means of pilot workshops.

\section{Materials and methods}

The longitudinal teaching concept targets three time points throughout the education program: (1) the team assistance seminar, required for onboarding the Graz emergency medical service (EMS), (2) the basic seminar before picking up responsibility as a NKI-RM in training, and (3) the NKI seminar itself. The evaluation period ran from 2016-2018.

\section{Results}

The first part consisted of interactive workshops using training videos to facilitate active knowledge acquisition. The second part included the ZIN Obelisk game[2] for critical reflection and assessment of one's own behavior. The third part encompassed the active recognition and application of NTS using the NTS-Bingo[3]. Additionally, the team checklist by Cooper[4] was used in debriefing scenario-based simulations. Eight pilot workshops were conducted between 2016 and 2018.
Figure 1: Overview of the longitudinal teaching concept.

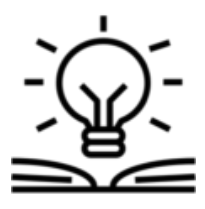

(1) KNOWLEDGE

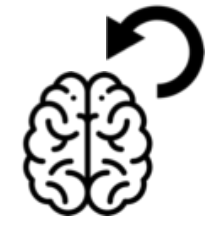

(2)

BEHAVIOURAL REFLEXTION

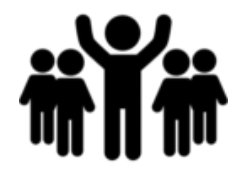

(3) PRACTICAL

\section{References}

[1] Advanced Life Support Group (2013) Human Factors in the Healthcare Setting. BMJ Books, Wiley-Blackwell.

[2] Francis D, Young D (1979). Improving work groups, a practical manual for team building. University Associates, San Diego, California.

[3] Dieckmann P, Glavin R, Jepsen RMHG, Krage R (2016) Non-Technical Skills Bingo - a game to facilitate the learning of complex concepts. Adv Simul 1:23

[4] Cooper S, Cant R, Porter J et al (2010) Rating medical emergency teamwork performance: development of the Team Emergency Assessment Measure (TEAM). Resuscitation 81(4):446-452

\section{Conclusion}

The amount of pilot workshops shows that a systematic integration of NTS in an educational program is feasible within a short time span. The administration of different teaching tools takes into account the progress during the educational program. The application of active teaching methodologies should guarantee a high degree of educational sustainability aiming for a practical application of NTS in the Graz EMS. A follow-up project for an in-depth analysis of effects of the integration of NTS in the educational program is being planned.
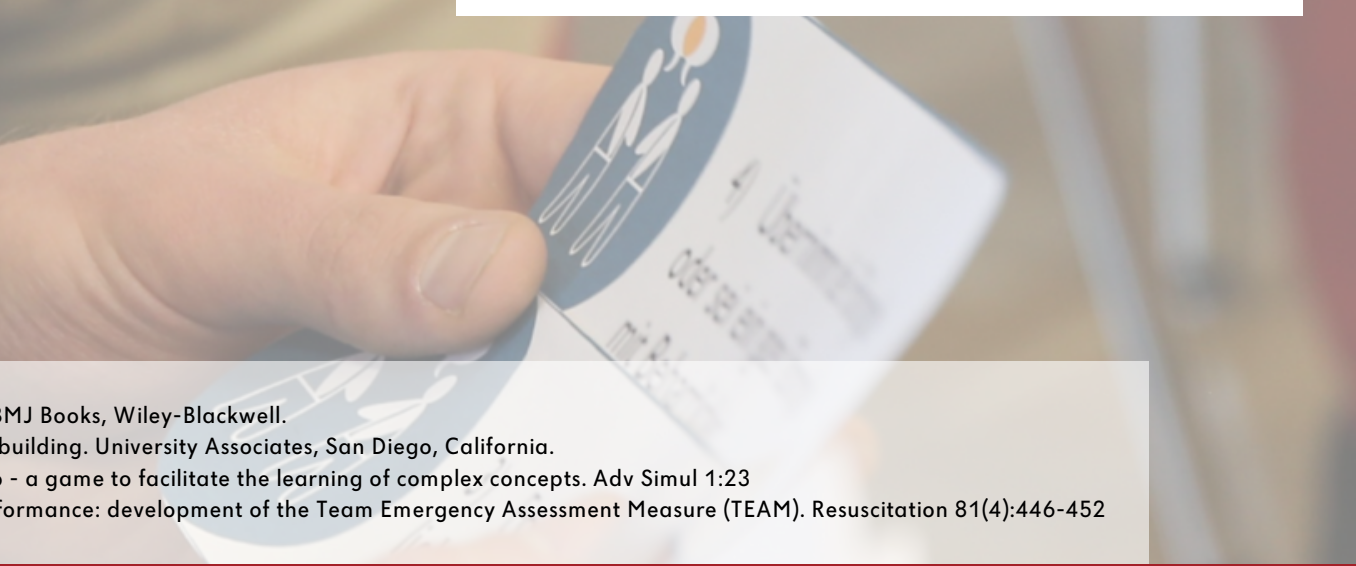

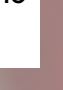
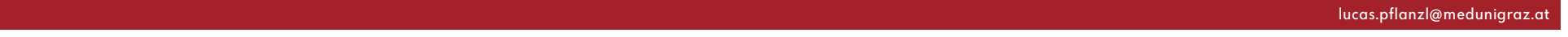